\title{
Mitteilungen der ÖGIAIM
}

Med Klin Intensivmed 2012 • 107:160-160

DOI 10.1007/s00063-012-0102-5

(C) Springer-Verlag 2012

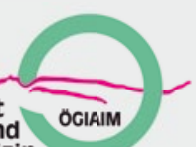

Allgemeine Intensivmedizin

\section{Österreichische Gesellschaft für Internistische} und Allgemeine Intensivmedizin

\section{Sekretär}

Univ.-Prof. Dr. S. Dunzendorfer

Medizinische Universität Innsbruck

Anichstraße 35, 6020 Innsbruck

Tel. +43 (512) 504-81302

Fax +43 (512) 504-24199

Stefan.Dunzendorfer@i-med.ac.at

www.intensivmedizin.at

\section{Veranstaltungshinweis}

\section{ANV \& Hämofiltrations- seminar 2012}

\section{Das Akute Nierenversagen auf der Intensivstation}

11./12. Mai 2012

Kongress \& TheaterHaus,

Bad Ischl, Österreich
Es sind noch Plätze verfügbar: Anmeldung bitte per E-Mail (office@kongressmanagement.at) oder direkt über die online-Anmeldung auf der ÖGIAIM Homepage (www. intensivmedizin.at).

\section{ANV \& HÄMOFILTRATIONS-}

\section{SEMINAR 2012}

(für ÄrztInnen und Pflegepersonen)

\section{Das Akute Nierenversagen auf der Intensivstation}

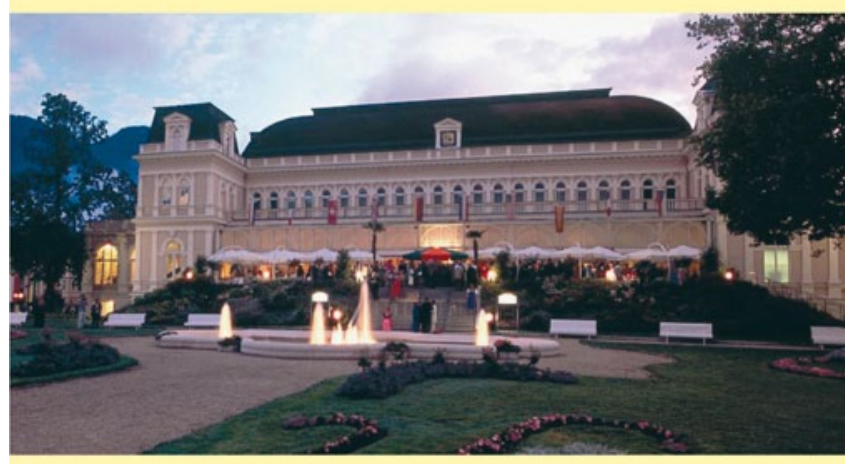

\section{FASIM}

Federation of Austrian Societies of Intensive Care Medicine - verband der intensiv-
medizinischen cesellschaften Osterreichs

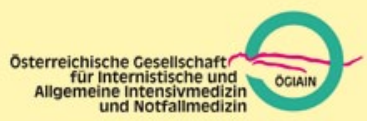

11. und 12. Mai 2012

Kongress \& TheaterHaus, Bad Ischl 